\title{
SIMS/XPS Studies of Surface Layer Formed in Fe-Si-Mn Alloys by Oxygen Penetration
}

\author{
Shigeru SUZUKI, Haijme HASEGAWA, Shozo MIZOGUCHI and Yoshio WASEDA \\ Institute of Multidisciplinary Research for Advanced Materials, Tohoku University, Katahira, Aoba-ku, Sendai 980-8577 Japan.
}

(Received on July 4, 2002; accepted in final form on September 3, 2002)

\begin{abstract}
Secondary ion mass spectrometry (SIMS) and X-ray photoelectron spectroscopy (XPS) have been used for analyzing surface layers formed in Fe-Si-Mn alloys containing 1, 2, 3 and 4.5 mass \% silicon, which were annealed in hydrogen and argon gases with a low partial pressure of oxygen. SIMS depth profiles showed that silicon in these alloys is reacted with oxygen penetrating into the bulk to form silicon oxides, and the characteristic distribution of silicon oxides is obtained in the surface layer, depending on the bulk silicon concentration. Manganese in the alloys was also found to be enriched to the outer side of the surface layer. On the other hand, XPS results showed that silicon and manganese are enriched on the top surface in these alloys, and the surface concentration of these elements depends on the bulk silicon concentration.
\end{abstract}

KEY WORDS: secondary ion mass spectrometry; X-ray photoelectron spectroscopy; iron-silicon-manganese alloys; oxidation.

\section{Introduction}

Oxidation of iron base alloys is accompanied with complicated phenomena such as changes in chemical composition and morphology in a surface layer, which depend on the annealing conditions. ${ }^{1-7)}$ Reactive alloying elements are often selectively interacted with oxygen penetration into the bulk from an annealing atmosphere. The reactivity with oxygen and the diffusivity of alloying elements are known to affect on the oxidation behavior. Selective oxidation of alloying elements can occur in iron base alloys annealed under a low partial pressure of oxygen, in which iron is not oxidized. Since a surface layer containing such oxides, which influences the surface properties, can be formed during annealing a practical steel sheet. For instance, a surface layer formed on a steel sheet annealed in a low partial pressure of oxygen is known to influence the phosphotability ${ }^{8)}$ and hot dip galvanized coatings ${ }^{9,10)}$ of cold rolled steel sheet. Therefore, characterization of surface layers formed in iron base alloys by annealing is very important in order to obtain factors affecting the surface properties. ${ }^{11)}$ So far, the surface of steel sheets has been studied by surface analytical methods, such as X-ray photoelectron spectroscopy (XPS) and Auger electron spectroscopy (AES), which are sensitive to very thin surface layer. However, high-sensitive depth analysis such as secondary ion mass spectrometry (SIMS) is also indispensable to obtain information of a surface layer, in which penetrating oxygen is reacted with reactive elements.

The aim of the present work is to characterize the distribution of elements in surface layers formed in $\mathrm{Fe}-\mathrm{Si}-\mathrm{Mn}$ alloys, which is very fundamental system in commercial steel iron base alloy, using SIMS. The chemical composition and state of the sample surface were also analyzed using XPS.

\section{Experimental}

\subsection{Sample Preparation}

Iron base alloys containing different amounts of silicon and a constant amount of manganese were prepared, in order to investigate the effect of silicon in the formation of surface layers and the distribution of manganese in surface layers. Buttons of $\mathrm{Fe}-\mathrm{Si}-0.5 \mathrm{mass} \% \mathrm{Mn}$ alloys with $1,2,3$ and 4.5 mass $\%$ silicon, which are hereafter referred to as $1 \% \mathrm{Si}, 2 \% \mathrm{Si}, 3 \% \mathrm{Si}$ and $4.5 \% \mathrm{Si}$, were prepared by arc melting. The method for sample preparation is identical to the previous case on in-situ observation of the microstructure of these alloys. ${ }^{12,13)}$ The chemical compositions of the alloys prepared in this work are listed in Table 1. Parts of the buttons were rolled to sheets of $0.5 \mathrm{~mm}$ in thickness. They were homogenized by annealing at $1273 \mathrm{~K}$ for $10^{4} \mathrm{~s}$, and then annealed in $9.8 \% \mathrm{H}_{2}-\mathrm{Ar}$ gas with the $\mathrm{H}_{2} \mathrm{O} / \mathrm{H}_{2}$ ratio of about 0.2 to remove residual carbon in these alloys. After they were mechanically polished, they were finally annealed at $1023 \mathrm{~K}$ for $1800 \mathrm{~s}$ in $9.8 \% \mathrm{H}_{2}-\mathrm{Ar}$ gas with the $\mathrm{H}_{2} \mathrm{O} / \mathrm{H}_{2}$ ratio of 0.07 . This ratio corresponds to the partial pressure

Table 1. Chemical composition of samples used. (mass\%)

\begin{tabular}{|l|l|l|l|l|l|}
\hline Sample & $\mathrm{Si}$ & $\mathrm{Mn}$ & $\mathrm{P}$ & $\mathrm{S}$ & $\mathrm{O}$ \\
\hline $1 \% \mathrm{Si}$ & 1.01 & 0.41 & 0.003 & 0.015 & 0.0006 \\
\hline $2 \% \mathrm{Si}$ & 1.91 & 0.38 & $<0.002$ & 0.014 & 0.0009 \\
\hline $3 \% \mathrm{Si}$ & 2.93 & 0.36 & 0.002 & 0.014 & 0.0012 \\
\hline $4.5 \% \mathrm{Si}$ & 4.49 & 0.40 & 0.003 & 0.014 & 0.0023 \\
\hline
\end{tabular}


of oxygen of $8 \times 10^{-14} \mathrm{~Pa}$ at $1023 \mathrm{~K}$, in which iron in alloys is not oxidized while silicon is oxidized.

\subsection{Measurements}

SIMS measurements were carried out using PHI-6600 with quadrupole-type mass spectrometer. An incident beam of $5.0 \mathrm{keV} \mathrm{Cs}^{+}$ions was irradiated to the sample surface, and positive secondary ions were detected. In order to avoid interference of different kind ions, positive ions of ${ }^{30} \mathrm{Si}^{+}$, ${ }^{55} \mathrm{Mn}^{+},{ }^{144}(\mathrm{CsO})^{+}$and ${ }^{189}(\mathrm{CsFe})^{+}$were selected. It has been confirmed that depth profiles for iron based alloys by these ions are almost consisted with were quantitative depth profiles obtained by glow discharge optical emission spectrometry, in which the matrix effect is small. ${ }^{6,7)}$ In addition, since the matrix effect of $\mathrm{CsM}^{+}$ions is known to be relatively small, as reported in previous works, ${ }^{14-16)}$ depth profiles of these ions are considered to reasonably correspond to depth distribution of silicon, manganese, oxygen and iron. A surface profiler, Dektak-3, was used for measuring the depth sputtered by SIMS. The sputtering rate was estimated to be about $1.4 \mathrm{~nm} \cdot \mathrm{s}^{-1}$ from the measured sputtered depth and sputtering time in the present condition.

The surface chemical composition and state of samples were analyzed by X-ray photoelectron spectroscopy (XPS), PHI-5600. The operation conditions have already been described elsewhere. ${ }^{17,18)}$ The incident X-ray was monochromatized Al-K $\alpha$ and the analysis area was about $1 \mathrm{~mm}$ in diameter. XPS spectra were measured after the sample surface was slightly sputtered by argon ions, in order to remove a contaminated carbon layer from the sample surface. The surface chemical composition was evaluated from XPS spectra coupled with relative sensitive factors given in the apparatus.

\section{Results and Discussion}

\subsection{Changes in the Amounts of Elements in Surface Layer by Annealing}

By annealing samples in the low partial pressure of oxygen, oxygen penetrates into the samples to form a surface layer containing oxides of reactive elements. Changes in the amounts of oxygen and metallic elements in the surface layer by annealing can be evaluated by total secondary ion counts from a layer of about $5 \mu \mathrm{m}$ thick. Figure 1 shows the total secondary ion counts of $\mathrm{CsFe}^{+}, \mathrm{Mn}^{+}, \mathrm{Si}^{+}$and $\mathrm{CsO}^{+}$as a function of the bulk silicon concentration of these alloys. The amounts of oxygen and silicon in the surface layer increase with increasing bulk silicon concentration. The $\mathrm{Si}^{+}$count is not simple attributed to silicon in the bulk, but silicon enriched in the surface layer to form oxides. Therefore, the correlation between $\mathrm{Si}^{+}$and $\mathrm{CsO}^{+}$indicates that silicon oxides, presumably being mainly $\mathrm{SiO}_{2}$, are formed in surface layer, and the amount of the silicon oxides increases with increasing bulk silicon concentration.

The $\mathrm{CsFe}^{+}$counts, which are mainly attributed to metallic iron, appear to depend on the bulk silicon concentration in a complicated manner. This is considered to result from the matrix effect on occurrence of the secondary ions, since oxide particles are distributed in the surface layer. Manganese is likely to be oxidized in the surface layer, but a monotonic change in the amount of manganese in the sur- face layer by the bulk silicon concentration was not observed. This implies that manganese may be distributed in the surface layer to form oxides, presumably manganese silicate.

\subsection{Depth Profiles by SIMS}

Figures 2(a) and 2(b) show depth profiles of $\mathrm{CsFe}^{+}$,

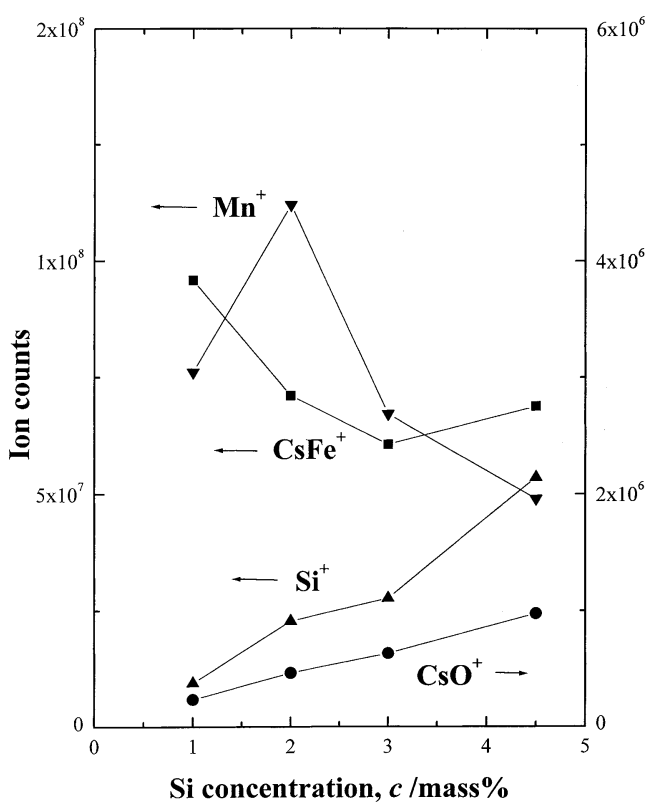

Fig. 1. Secondary ion counts from a surface layer formed by annealing as a function of the bulk silicon composition of the present $\mathrm{Fe}-\mathrm{Si}-\mathrm{Mn}$ alloys.

(a) $1 \% \mathrm{Si}$

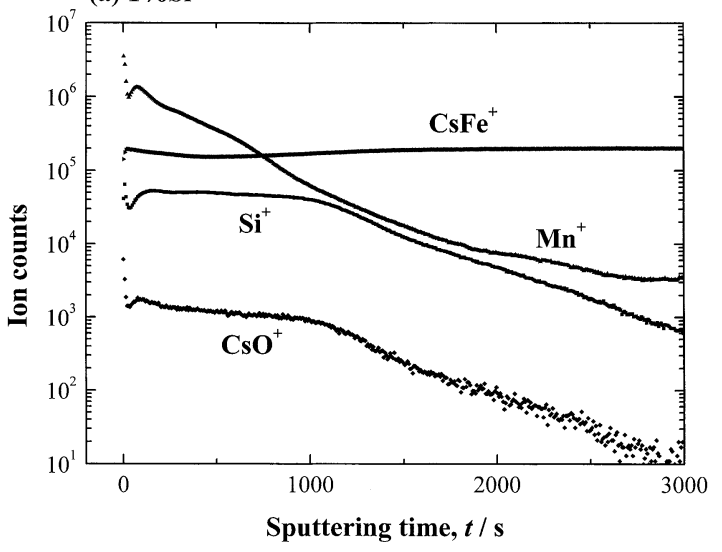

(b) $3 \% \mathrm{Si}$

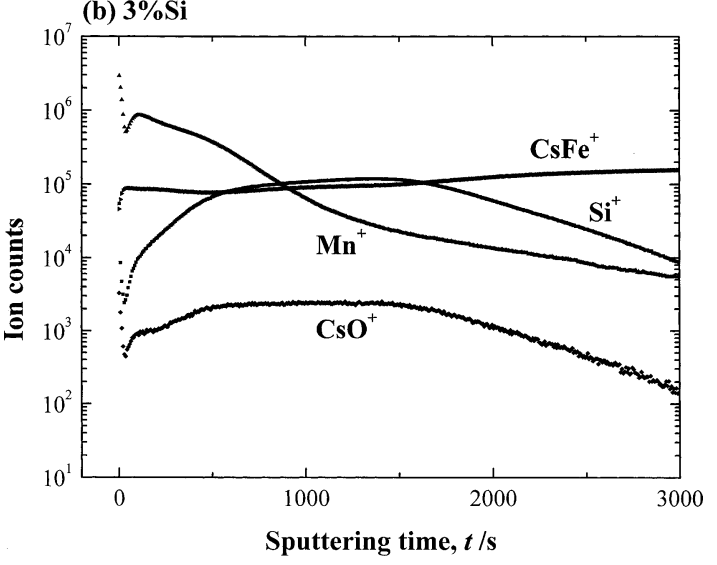

Fig. 2. SIMS depth profiles of $\mathrm{CsFe}, \mathrm{Mn}, \mathrm{CsO}$ and $\mathrm{Si}$ for surface layers formed in (a) $1 \% \mathrm{Si}$ and (b) $3 \% \mathrm{Si}$. The ion counts are plotted in logarithm scale. 
$\mathrm{Mn}^{+}, \mathrm{Si}^{+}$and $\mathrm{CsO}^{+}$, in $1 \% \mathrm{Si}$ and $3 \% \mathrm{Si}$, respectively. These ion counts are plotted in logarithm scale in these depth profiles for investigating the distribution of a small amount of elements. The sputtered depth for $3000 \mathrm{~s}$ in the present conditions was about $4.2 \mu \mathrm{m}$. The ion counts of $\mathrm{Si}^{+}$ in these depth profiles are clearly correlated with those for $\mathrm{CsO}^{+}$, indicating that silicon oxides are formed in the surface layer. This is consistent with the conclusion on dependence of the bulk silicon concentration on the total counts of $\mathrm{Si}^{+}$and $\mathrm{CsO}^{+}$, as shown in Fig. 1. These silicon oxides are formed by reaction of oxygen penetrating from the surface with silicon diffusing outwards from the bulk. However, it should be noted that the ion counts of $\mathrm{CsO}^{+}$do not decrease with increasing depth, and the shape of the depth profiles for $3 \% \mathrm{Si}$ is quite different from that for $1 \%$ $\mathrm{Si}$. If oxygen from the sample surface and silicon from the bulk are supplied to form oxide particles, which are separately distributed through the depth direction of the surface layer, such changes in depth profiles is not expected. This is attributed to the higher oxygen potential on the surface side, and the high activity of silicon in the alloy on the bulk side. Rather, the present depth profiles suggest that the effective front of reaction of silicon with oxygen and the distribution of oxide particles may depend on the bulk silicon concentration. On the other hand, the ion counts of $\mathrm{Mn}^{+}$almost decrease with increasing depth in these alloys, although some step is observed in the surface side of depth profiles. This indicates that manganese is enriched to the surface side to form oxides, presumably being mainly manganese silicates, which is induced by the oxygen potential on the surface side. The ion counts of $\mathrm{CsFe}^{+}$are slightly reduced in the surface layer containing oxides, which is likely to arise from the matrix effect on the secondary ions.

In order to compare the whole distribution of elements in surface layers of $1 \% \mathrm{Si}, 2 \% \mathrm{Si}, 3 \% \mathrm{Si}$ and $4.5 \% \mathrm{Si}$, depth profiles in which ion counts are plotted in linear scale are shown in Figs. 3(a), 3(b), 3(c) and 3(d). The level of ion counts of $\mathrm{CsO}^{+}$and $\mathrm{Si}^{+}$are adjusted by a factor for semiquantitative comparison. Differences in these depth profiles indicate that the distribution of silicon oxide particles formed in the surface layers is influenced by the bulk silicon concentration. The silicon oxide particles formed in the surface layers are likely to be interconnected to form network, since the depth profiles of $\mathrm{CsO}^{+}$and $\mathrm{Si}^{+}$rather depend on the depth.

\subsection{Surface Composition and State by XPS}

XPS was used for analyzing the chemical composition and state of the top surface layer within a few nanometers thick, since SIMS depth profiles hardly provide information on the chemical composition and state in the surface layer. Figures 4(a) and 4(b) exemplify the XPS wide spectra from the surface of $1 \% \mathrm{Si}$ and $3 \% \mathrm{Si}$, respectively. These spectra show that silicon and manganese are enriched to the top surface layer, and the surface concentration of these elements depends on the bulk silicon concentration. Segregation of residual elements is sometimes observed on the surface of iron-silicon alloys by annealing at high temperatures, ${ }^{19)}$ however, such segregation was not observed in this work. The surface concentrations of the present alloys annealed in a low partial pressure of oxygen were estimated
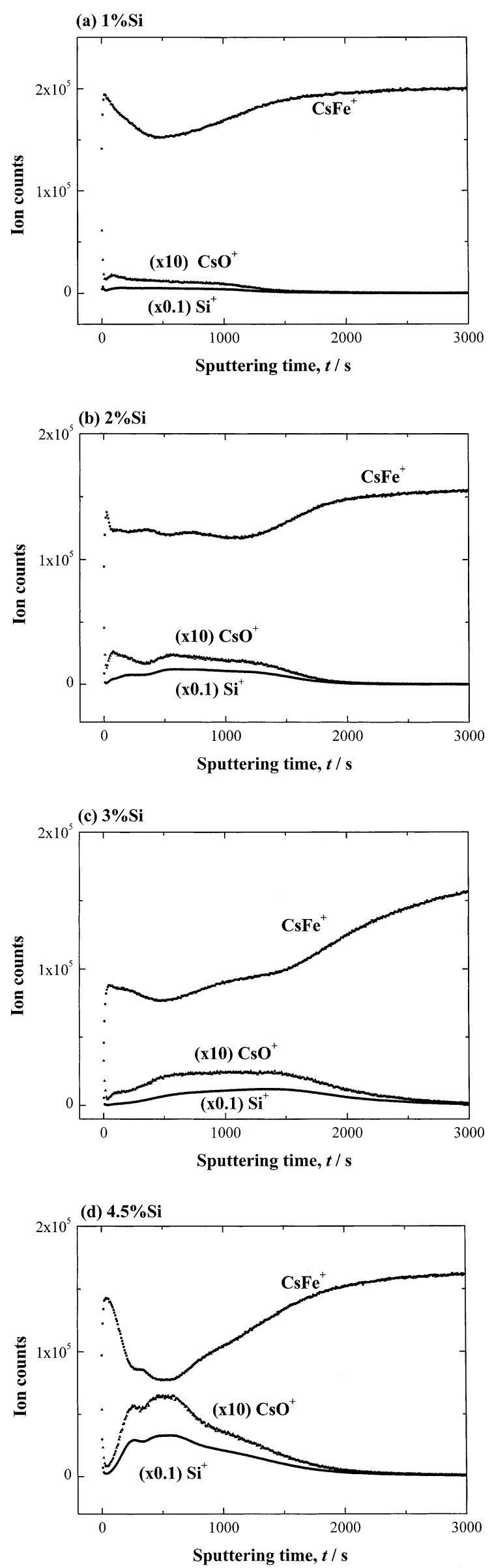

Fig. 3. SIMS depth profiles of $\mathrm{CsFe}, \mathrm{Mn}, \mathrm{CsO}$ and $\mathrm{Si}$ for surface layers formed in (a) $1 \% \mathrm{Si}$, (b) $2 \% \mathrm{Si}$, (c) $3 \% \mathrm{Si}$ and (d) $4.5 \% \mathrm{Si}$. The ion counts are plotted in linear scale. 


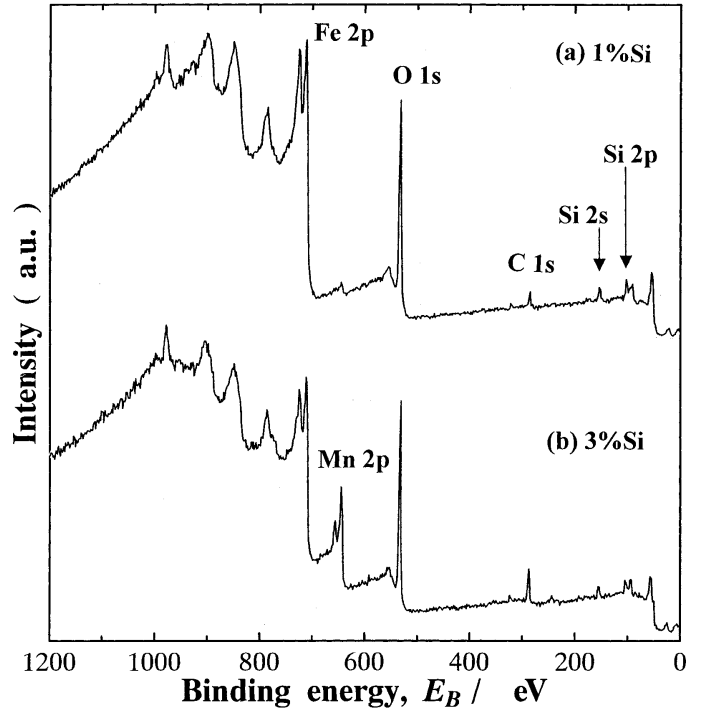

Fig. 4. XPS wide spectra from the surface of (a) $1 \% \mathrm{Si}$ and (b) $3 \% \mathrm{Si}$.

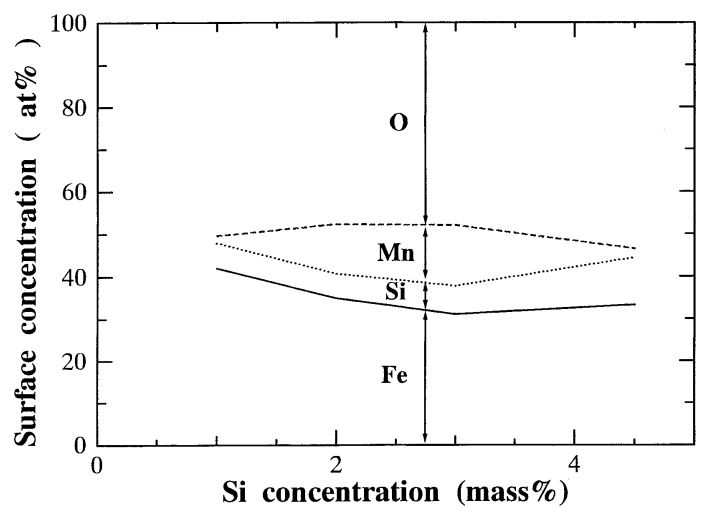

Fig. 5. The surface concentration obtained by XPS versus the bulk silicon concentration.

from peak area of the XPS narrow spectra, as a function of the bulk silicon concentration, as shown in Fig. 5. Oxygen measured in the present experiments is attributed to the oxide formed during annealing and the native oxide formed by air exposure after annealing. Silicon, manganese and a part of iron are oxidized during annealing to form silica, manganese silicate and iron silicate. The other part of measured oxygen is originated from the native oxide, which is formed by reaction of metallic iron on the sample surface with oxygen gas. The surface concentration appears not to be changed by the bulk silicon concentration, suggesting that the species and amounts of oxides formed on the sample may be influenced by oxides formed inside.

Figures 6 shows O $1 \mathrm{~s}$ XPS spectra from the surface of $1 \% \mathrm{Si}, 2 \% \mathrm{Si}, 3 \% \mathrm{Si}$ and $4.5 \% \mathrm{Si}$. Two different peaks are observed at about 533.0 and $530.5 \mathrm{eV}$ in $1 \% \mathrm{Si}$ and $4.5 \%$ Si. The peaks at 533.0 and $530.5 \mathrm{eV}$ are allocated to $\mathrm{SiO}_{2}$ and iron oxides, respectively. ${ }^{20)}$ The peak at $530.5 \mathrm{eV}$ is considered to include information of the native oxide, iron silicate and manganese silicate. ${ }^{11,18,20)}$ This peak is dominant in the spectra of $2 \% \mathrm{Si}$ and $3 \% \mathrm{Si}$, which is consistent with the fact that manganese is considerably enriched to the top surface of these alloys, as shown in Fig. 5.

Si $2 p$ XPS spectra from the surface of the present samples are given in Fig. 7, although the spectra appear to be

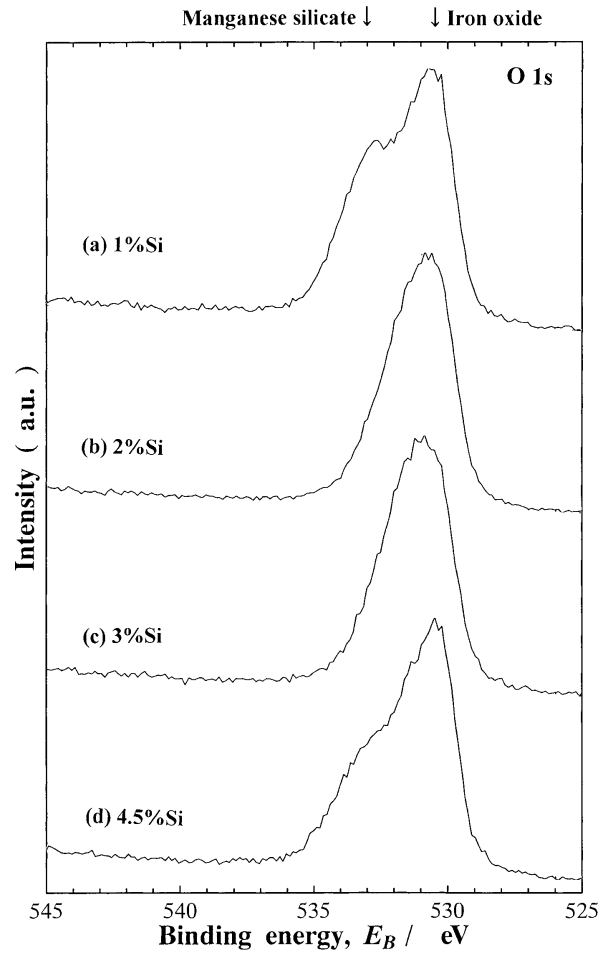

Fig. 6. O 1s XPS spectra from the surface of (a) $1 \% \mathrm{Si}$, (b) $2 \%$ $\mathrm{Si},(\mathrm{c}) 3 \% \mathrm{Si}$ and (d) $4.5 \% \mathrm{Si}$

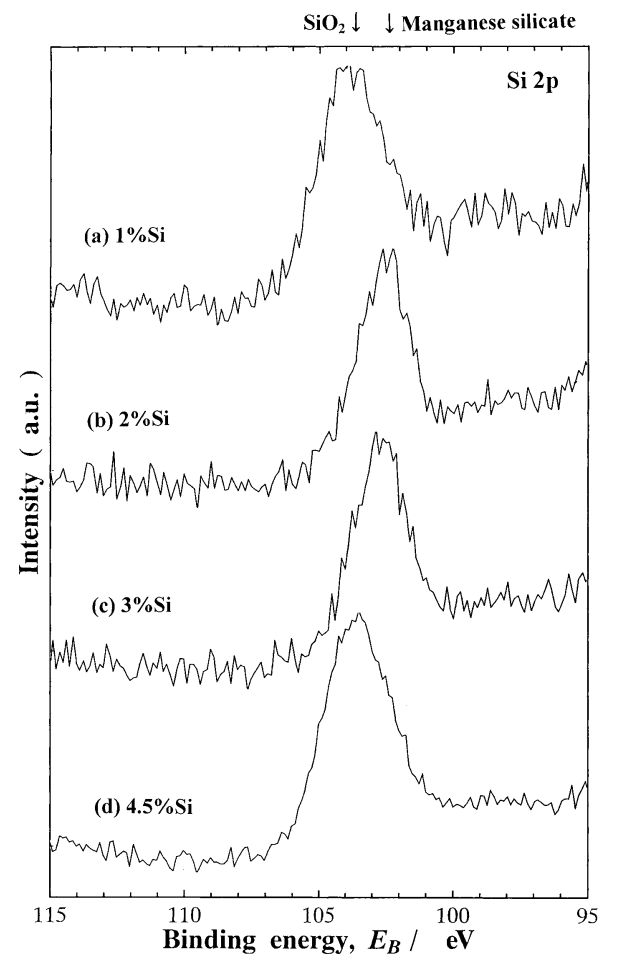

Fig. 7. Si $2 p$ XPS spectra from the surface of (a) $1 \% \mathrm{Si}$, (b) $2 \%$ $\mathrm{Si}$, (c) $3 \% \mathrm{Si}$ and (d) $4.5 \% \mathrm{Si}$.

noisy for the relatively low sensitivity of Si $2 \mathrm{p}$. A peak between 103.5 and $104.0 \mathrm{eV}$ in $1 \% \mathrm{Si}$ and $4.5 \% \mathrm{Si}$ and a peak at about $102.5 \mathrm{eV}$ in $2 \% \mathrm{Si}$ and $3 \% \mathrm{Si}$ are observed in these spectra. According to previous data on silicates, ${ }^{7,11)}$ these results indicate dominant formation of $\mathrm{SiO}_{2}$ on the surface of $1 \% \mathrm{Si}$ and $4.5 \% \mathrm{Si}$ and formation of manganese or iron silicate on the surface of $1 \% \mathrm{Si}$ and $4.5 \% \mathrm{Si}$, which is also consistent with the results as shown in Fig. 5. In addition, 


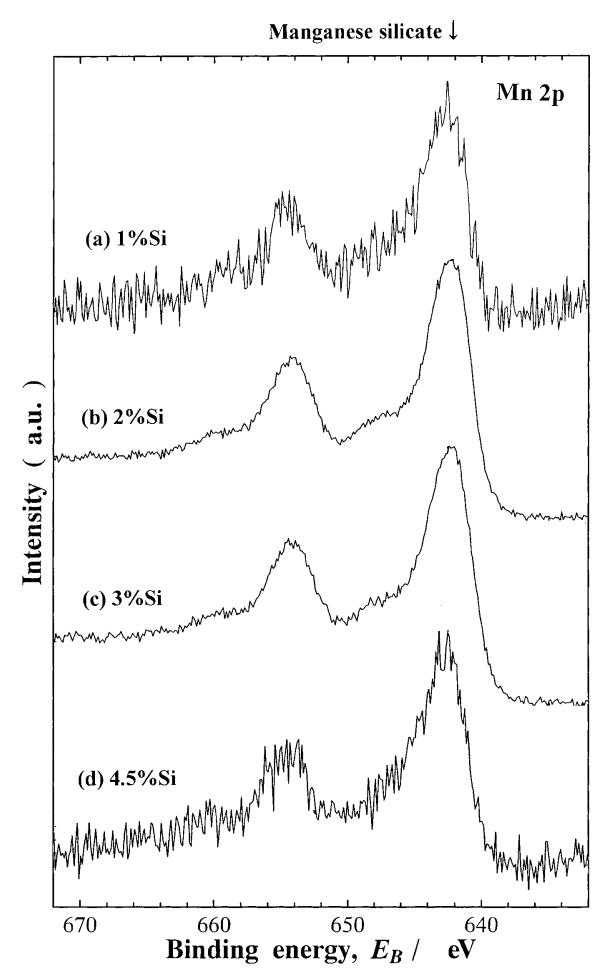

Fig. 8. Mn $2 p$ XPS spectra from the surface of (a) $1 \% \mathrm{Si}$, (b) $2 \% \mathrm{Si}$, (c) $3 \% \mathrm{Si}$ and (d) $4.5 \% \mathrm{Si}$.

Mn 2p XPS spectra from the surface of the present samples is shown in Fig. 8, although the signal to noise ratio in $1 \%$ $\mathrm{Si}$ and $3 \% \mathrm{Si}$ is low because of the low manganese concentration on the sample surface. These results indicate that manganese is present mainly as manganese silicate. ${ }^{7,11)}$

\subsection{Characteristic Features of Formation of Surface Layer}

In a simple case of oxygen penetration into alloys, a monotonic decrease is expected in the oxygen concentration as a function of the depth. The shape of the distribution of oxides of alloying elements formed by oxygen penetration would be almost independent on the bulk concentration of alloying elements. In practice, such distribution of oxygen has been found in a copper-titanium alloy system, in which only titanium is reacted with oxygen penetrating into the alloys in a low partial pressure of oxygen. ${ }^{21)}$ On the other hand, the penetration behavior of oxygen in the present $\mathrm{Fe}-\mathrm{Si}-\mathrm{Mn}$ system appears to be quite different from the simple case. Figure 9 illustrates a schematic diagram for the surface layers formed in $\mathrm{Fe}-\mathrm{Si}-\mathrm{Mn}$ alloys with different bulk silicon composition by oxygen penetration. Characteristic distribution of oxygen and alloying elements are found; the monotonic decrease in the oxygen concentration is not observed in the depth profiles, and the distribution of silicon oxides is influenced by the bulk silicon concentration. In the $\mathrm{Fe}-\mathrm{Si}-\mathrm{Mn}$ system with low silicon concentration, silicon oxide particles are dispersed, and do not seem to be interconnected. Thus, the amount of oxygen is almost likely to decrease with increasing the depth, as shown in Fig. 2(a). As the bulk silicon concentration increases, the surface layer containing silicon oxide particles becomes thicker and silicon oxide particles are interconnected. Such features correspond to the results shown in Fig. 2(b). The density of strongly interconnected silicon oxides in the sur- (a)

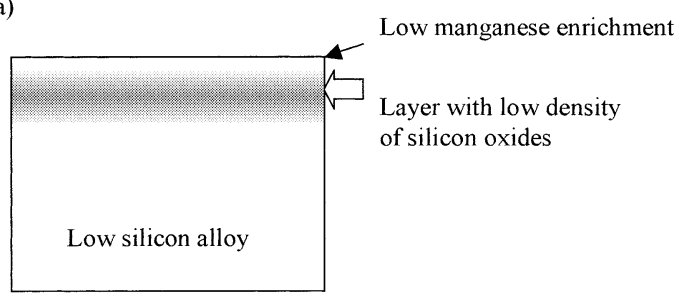

(b)
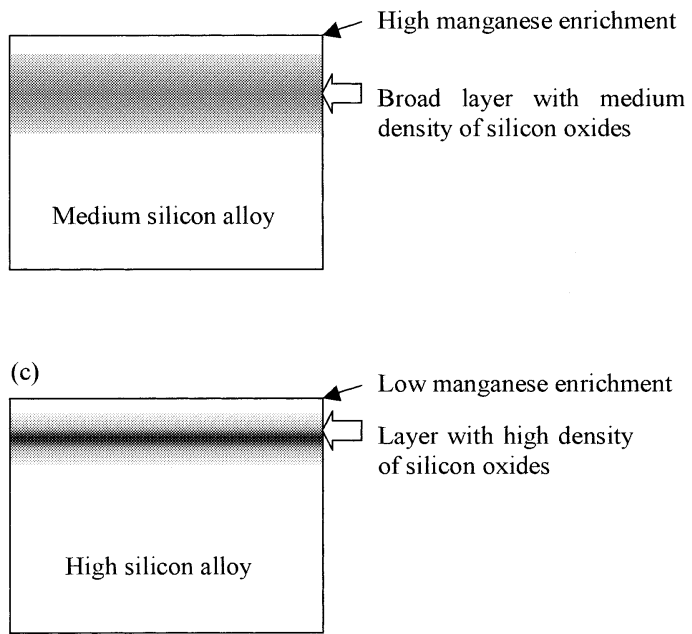

Fig. 9. Schematic diagram for formation of surface layers in $\mathrm{Fe}-\mathrm{Si}-\mathrm{Mn}$ alloys with (a) low amount, (b) medium amount and (c) high amount of silicon by annealing in a partial pressure of oxygen.

face layer may be high in $4.5 \% \mathrm{Si}$, as shown in Fig. 3(d). Growth of such networks of oxide particles is considered to induce extrusion of metallic iron from the network. This is the reason why the an iron enriched layer is observed in the surface side of the depth profile of iron, as shown in Fig. 3(d). Among the distribution of silicon oxides, manganese seems to contribute to formation of surface layers, particularly oxides formed on the surface. This is because manganese is reacted with silicon oxides to form manganese silicate, ${ }^{22)}$ of which the physical and chemical properties are likely to considerably different from those for silicon oxides.

\section{Concluding Remarks}

SIMS and XPS have been used for analyzing surface layers formed in Fe-Si-Mn alloys with 1, 2, 3 and 4.5 mass\% silicon, which were annealed in a low partial pressure of oxygen. The main results obtained are as follows:

(1) Silicon in these alloys is reacted with oxygen penetrating into these alloys to form silicon oxides. Characteristic distribution of silicon oxides formed in the surface layer is obtained, and it depends on the bulk silicon concentration of these alloys. Manganese is enriched to the outer side of the surface layer.

(2) Silicon and manganese are enriched on the top surface in these alloys, and the surface concentration of these elements appears not to vary by the bulk silicon concentration. On the other hand, the chemical state information of elements on the surface is consistent with the surface con- 
centration.

(3) The complicated distribution of elements in surface layers is considered to result form the properties of oxides such as silicon oxides and manganese and iron silicates formed during annealing.

\section{Acknowledgements}

The authors are grateful to Mr. T. Sato and Mr. M. Itoh for their help and maintenance of XPS apparatus.

\section{REFERENCES}

1) P. Kofstad: High Temperature Corrosion, Elsevier Applied Science, London, (1988), 324.

2) D. L. Douglass: Oxid. Met., 44 (1995), 81

3) M. Fukumoto, S. Hayashi, S. Maeda and T. Narita: Tetsu-to-Hagané, 85 (1999), 16.

4) M. Fukumoto, S. Maeda, S. Hayashi and T. Narita: Proc. High Temperature Corrosion and Protection 2000, ISIJ, Tokyo, (1999), 215.

5) W. Block and N. Jayaman: Mater. Sci. Technol., 2 (1986), 22.

6) K. Yanagihara, S. Suzuki and S. Yamazaki: Oxid. Met., 57 (2002), 281.

7) K. Yanagihara, S. Suzuki and S. Yamazaki: J. Surf. Anal., 9 (2002), 388 .

8) T. Usuki, A. Sakota, S. Wakano and M. Nishihara: Tetsu-to-Hagané,
77 (1991), 84.

9) T. Usuki and M. Hori: CAMP-ISIJ, 8 (1995), 647.

10) Y. Tsuchiya, S. Hashimoto, Y. Ishibashi, J. Inagaki and Y. Fukuda: Tetsu-to-Hagané, 86 (2000), 396.

11) T. Usuki, T. Takayama and M. Arai: CAMP-ISIJ, 4 (1991), 375.

12) H. Hasegawa, K. Nakajima and S. Mizoguchi: Tetsu-to-Hagané, 87 (2001), 433.

13) H. Hasegawa, K. Nakajima and S. Mizoguchi: Tetsu-to-Hagané, 87 (2001), 700 .

14) C. W. Magee, W. L. Harrington and M. Botnick: Int. J. Mass Spctrom. Ion Processes, 103 (1990), 45.

15) T. Gao, Y .Marie, F. Saldi and H.-N. Migeon: Int. J. Mass Spctrom. Ion Processes, 143 (1995), 11.

16) W. Dümmler, S. Weber, C. Tête and S. Scherrer: Int. J. Mass Spctrom. Ion Processes, 164 (1997), 155.

17) S. Suzuki, T. Kosaka, H. Inoue and Y. Waseda: Mater. Trans., JIM, 36 (1995), 1379.

18) S. Suzuki, Y. Ishikawa, M. Isshiki and Y. Waseda: Mater. Trans., JIM, 38 (1997), 1009.

19) S. Suzuki: Mater. Trans., JIM, 35 (1994), 35.

20) J. F. Moudler, W. F. Sticle, P. E. Sobol and K. Bomben: X-ray Photoelectron Spectroscopy, Physical Electronics, Minnesota, (1993), 213.

21) S. Suzuki, K. Hirabayashi, K. Mimura, T. Okabe, M. Isshiki and Y. Waseda: Mater. Trans., 43 (2002), 2303.

22) S. K. Saxena, N. Chatterjee, Y. Fei and G. Shen: Thermodynamic Data on Oxides and Silicates, Springer-Verlag, Heidelberg, (1993), 116. 